\title{
Midwives experiences as preceptors and the development of good preceptorships in obstetric units
}

S. Zwedberg, Karin Forslund Frykedal, Michael Rosander, A. Berlin and M. Barimani

The self-archived postprint version of this journal article is available at Linköping University Institutional Repository (DiVA):

http:/ / urn.kb.se/ resolve?urn=urn:nbn:se:liu:diva- 167638

N.B.: When citing this work, cite the original publication.

Zwedberg, S., Forslund Frykedal, K., Rosander, M., Berlin, A., Barimani, M., (2020), Midwives experiences as preceptors and the development of good preceptorships in obstetric units, Midwifery, 87, UNSP 102718. https:// doi.org/ 10.1016/j.midw.2020.102718

Original publication available at:

https:// doi.org/ 10.1016/j.midw.2020.102718

Copyright: Elsevier

http:// www.elsevier.com/

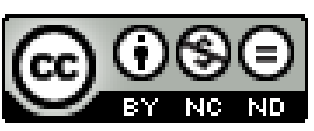




\section{Midwives' experiences as preceptors and the development of good preceptorships in obstetric units}

Sofia Zwedberg ${ }^{\mathrm{a}, \mathrm{b}}$, Karin Forslund Frykedal ${ }^{\mathrm{c}}$, Michael Rosander ${ }^{\mathrm{c}}$, Anita Berlin ${ }^{\mathrm{d}}$, Mia Barimani $^{\mathrm{e}, \mathrm{f}}$

aDepartment for Health Promotion Science, Sophiahemmet University, Stockholm, Sweden

bChildrens \& Woments’ Health Theme PA Pregnancy Care and Delivery, Karolinska University hospital, Solna, Sweden

cDepartment of Behavioral Sciences and Learning, Linköping University, Linköping, Sweden

${ }^{\mathrm{d}}$ The Division of Nursing Department of Neurobilogy, Care Sciences and Society, Karolinska Institutet, Huddinge, Sweden

'The Division of Family Medicine and Primary Care, Department of Neurobiology, Care Scienses and Society, Karolinska Institutet, Huddinge, Sweden

${ }_{\mathrm{f}}^{\mathrm{f}}$ Academic Primary Care Centre, Region Stockholm, Stockholm, Sweden

\section{Abstract}

Objective: To study midwives’ experience in their role as a preceptor and their perception on how to best support midwifery students in obstetrics units. Obstetric units are an important learning area for student midwives but knowledge on how to become a good midwife preceptor is limited.

Design: This qualitative study explores midwife preceptors’ experience of supervising midwifery students in three obstetric units in Sweden. Following ethical approval seventeen midwife preceptors were interviewed and data were analysed thematically.

Findings: Thematic analysis of the interviews resulted in the identification of two themes and five subthemes: 1) self-efficacy in the preceptor role which involves a) being confident in the professional position and b) having the support of management and colleagues and 2) supporting the student to attain self-confidence and independence which entails a) helping the student to grow, b) facilitating reflection in learning situations, and c) "taking a step back". 
Key conclusion: Good preceptorship occurs when midwives achieve full self-efficacy, when they master the preceptor role, and when they have enhanced their abilities to help, the student reach confidence and independence.

Implications for practice: Health care organisations needs to develop and support midwifery preceptorships.

Keywords Preceptors; Midwifery; Student midwives; Clinical placements

\section{Introduction}

Clinical placements are an important learning stage for student midwives. Obstetric units are especially challenging, mainly due to stressful working conditions, high student enrolment, and limited clinical placement opportunities for the students (McKellar and Graham 2017). Clinical preceptors are midwives who guide and support students during clinical placements. Precepting is used in clinical education in many health care professions. It is a teaching learning approach that employs a one-to-one relationship between an experienced practitioner and a student (McClure and Black 2013). In Sweden, midwives are the occupational group responsible for normal pregnancy, labour, childbirth, and postnatal care. The profession also entails the supervision and education of students, however, education in preceptorship is not mandatory. Swedish midwifery education lasts 18 months and is based on a three-year nursing programme (Bachelor's degree). Midwives in training have to assist at 50 births and care for at least 100 women in labour. The typical model of midwifery clinical training is based on apprenticeship with interactions between students and preceptors. This study focuses on the role of the clinical midwifery preceptor (hereinafter preceptor or midwife) in obstetric units.

Research about midwifery preceptorship and student midwives 
The existing body of literature exploring preceptorship and student midwives (hereinafter students) consists mostly of students expressing vulnerability during their internship (Back et al. 2017; Brunstad and Hjalmhult 2014; Davies and Coldridge 2015; Licqurish and Seibold 2008; Licqurish and Seibold 2013; Schytt and Waldenstrom 2013; Thunes and Sekse 2015). For example, students tend to worry about receiving sufficient support and supervision from their preceptor (Davies and Coldridge 2015) or about being ill-prepared for clinical practice (McIntosh et al. 2013). In addition, they are often insecure about their ability to manage medical complications (Back et al. 2017; Davies and Coldridge 2015; Schytt and Waldenstrom 2013). Students also stated that reflection with the preceptor was an important factor to facilitate learning (Brunstad and Hjalmhult 2014; Ekelin et al. 2016; Embo et al. 2015; Longworth 2013). There is ample evidence that highlights the importance of good preceptorship (Davies and Coldridge 2015; Gilmour et al. 2013; Hughes and Fraser 2011; Licqurish and Seibold 2008; McKellar and Graham 2017; Moran and Banks 2016; Thunes and Sekse 2015). The relationship between student and preceptor has been pointed out as fundamental for the students to gain confidence in clinical practice (Brunstad and Hjalmhult 2014; Hughes and Fraser 2011; Licqurish and Seibold 2013; Thorstensson et al. 2008; Thunes and Sekse 2015). The preceptor has a range of key roles to play in the learning process. These key roles include engagement, reflections, and encouragement to make the best of each learning situation (Hughes and Fraser 2011; Thunes and Sekse 2015).

\section{Theoretical framework}

The midwife's role as a preceptor is important in developing the students’ confidence and abilities to practice midwifery (Jordan and Farley 2008). An accomplished preceptor should be able to demonstrate self-efficacy, i.e., the perceived ability to perform a specific task or behaviours in the role (Bandura 1982). Self-efficacy is a significant concept in social cognitive theory (Bandura 1982) which states that individuals in social systems learn from 
each other by observation, imitation, and modelling. Self-efficacy is influenced by (a) experiences of one’s own performance accomplishments, (b) vicarious experience gained from important role models, primarily through direct observation, (c) emotional arousal during the performance of a particular behaviour, and (d) verbal persuasion provided by others while attempting the behaviour (Bandura 1982). Bandura (1982) also showed that the higher the level of perceived self-efficacy for achieving a specific task or behaviour, the higher the level of performance accomplishment, and vice versa. Outcome expectancy, i.e., an individual's belief that a particular behaviour will yield a valuable outcome, is a prerequisite for the development of self-efficacy for a specific behaviour. For example, a preceptor must believe that reflections between preceptor and student are important to facilitate student learning before they will enact the behaviour. Bandura (1993) argued that the belief that one can control events of importance and produce favourable outcomes will lead to an increased input of effort and persistence into a given task.

Assuming that a preceptor's self-efficacy plays a fundamental role for the students to achieve confidence and have successful learning outcomes, our aim is to study midwives' experiences in their role as preceptor and their perception on how to best support midwifery students in obstetrics units.

\section{Method}

A qualitative approach was chosen to explore the context of preceptorship.

\section{Data collection and participants}

Midwives in three obstetric units in a large city in Sweden were informed about the study and asked to participate. Experience in preceptorship was a mandatory inclusion criterion. 
Seventeen midwives who met the inclusion criterion agreed to participate in the study. Interviews were held between October 2018 and March 2019 in these units (three interviews were held by telephone following a request by the participants). Mean age was 55 years old (age range between 35-65 years old) and mean time for clinical experience was 18 years (range: 4 to 35 years). Seven participants had undertaken a course in preceptorship for at least five weeks. Semi-structured interviews were conducted, the length of which ranged from 20 to 45 min (mean: $30 \mathrm{~min}$ ). The semi-structured interviews included questions about the experience of having students and experience of being preceptors. Participants were also encouraged to describe situations that generated good preceptorship. All interviews were audio recorded and transcribed verbatim yielding about 97 pages of double spaced text.

\section{Analysis}

Data were analysed using a six-stage thematic approach (Braun 2006). At the first stage, all transcribed interviews were read repeatedly to get an overview and a deeper understanding of the material. The focus was to find patterns of meaning and issues of potential interest in the data related to the research questions. At the second stage, features of interest were identified and assigned codes. At the third stage, the relationship between codes was investigated and they were sorted into potential themes and subthemes, which revealed two main foci: (a) preceptor role and (b) supporting the student. At the fourth stage, the themes were revised and refined by checking that the themes adequately represented the entire material. Further, the data within each theme were checked to see whether they were coherent and meaningful and to verify whether both themes were clearly identifiable and distinguishable. In the fifth stage, the themes and subthemes were defined (Figure 1). In the sixth and final stage, the findings that reflected established themes were compiled, and quotes were identified to highlight text 
variations. The six stages have not been a linear process, i.e., we did not start with stage one and ended in stage 6; it was rather a "back-and-forth"/circular process.

\section{Ethical considerations}

The study was approved by the Stockholm Regional Ethics Board (2017/1326-31/5).

\section{Findings}

The thematic analysis of the interviews resulted in the identification of two main themes and five subthemes (Figure 1).

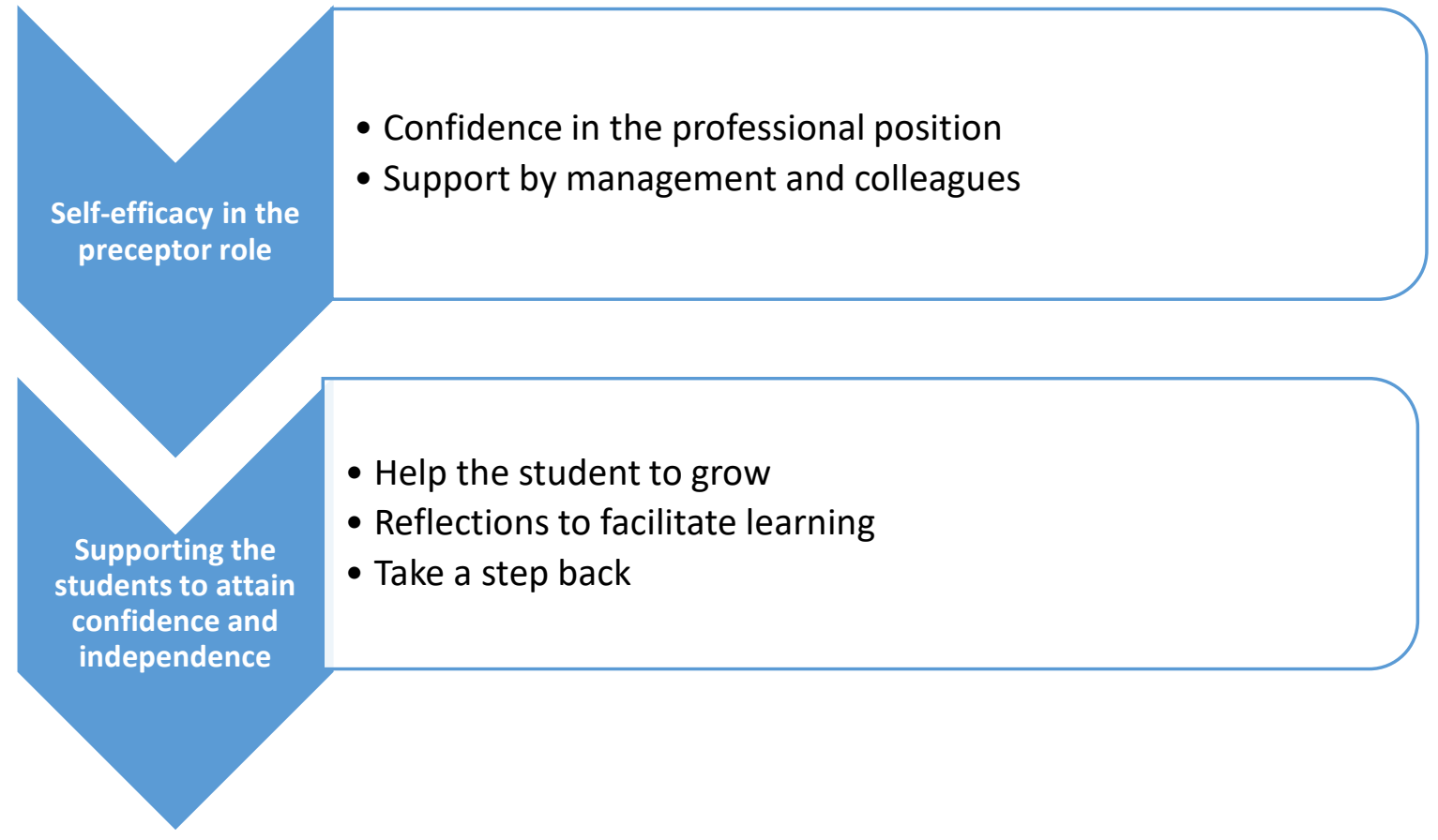

Figure 1. Themes and subthemes

\section{Self-efficacy in the preceptor role}

Confidence in the professional role 
Midwives stated that in order to feel confident in their role as preceptor, they needed to be confident that they had the necessary abilities for their role as midwife, i.e., they needed to perceive a high level of self-efficacy in their role as midwives before being able to assume the preceptor role. As one of the midwives stated:

"It's really important that you feel confident in your own role as a midwife and that you feel secure in your position before taking on a student who may not have found their own place just yet" (9)

A high level of proficiency in the professional role was equated with the ability to achieve a holistic approach, with being humble, with the ability to correctly understand and assess a situation, with having acquired a "clinical eye" through experience, and with the ability to handle an emergency situation:

"To know exactly what to do in an emergency situation is having a clinical eye, I think." (5)

To achieve security in the professional role, the midwives suggested a minimum period of 2 to 5 years of clinical experience. Preceptorship included being a role model and being able to support students, hence to help them develop their clinical competences. This was considered a big responsibility only actionable after many years of clinical experience:

"So, you have to have at least five years of practical experience as a midwife, before you become confident in your role and have acquired the necessary skills to supervise a student" (2)

A commonly stated problem was that midwives with less clinical experience were supervising students which many considered problematic since the profession requires a significant amount of professional experience as well as a holistic approach. Although recently trained 
midwives may have a more up-to-date theoretical knowledge, they also need to be able to have a footing in reality:

"It will take a long time before you are secure in your role. We try to reassure new colleagues that it takes time before they will feel confident” (13).

In order to supervise students, it was also important to keep up-to-date with academic knowledge by consulting current literature, guidelines, and participating in relevant courses. The midwives stated that by keeping up-to-date with advancements in theory they could carry out experience-based supervision integrated with theoretical knowledge, which allowed them to have the same level of theoretical knowledge as the students:

"In our profession the learning never stops, we work with people; people are different, society is changing and we are also changing. There will always be new procedures and in new approaches, we will never be fully-trained" (9).

The midwives also receive new knowledge from the students:

"It's not just the midwife who teaches the student, it's quite the opposite actually. Supervising a student also means to learn, because you need to verbalize what you do" (10).

\section{Support by management and colleagues}

In order to increase self-efficacy and improve the quality of the preceptorship, the midwives expressed the need for support from management in the form of preceptorship courses. They argued that courses could provide them with information on how to facilitate learning, how to provide the students with feedback, and how to fill the role of preceptor if the student has difficulties to reach the learning objectives or other personal problems. Midwives mentioned another reason that interfered with them fulfilling their roles as perceptor: the delegation of 
additional duties by the management. This can create a stressful work environment as students can require a significant amount of energy and attention as the preceptor needs to carry our additional work to double-check that everything was done correctly by the student. Regular breaks from preceptorship are thus important:

"I have to be completely honest and say that sometimes, it's very, very tough ... Yes, it can be tough ... It is not just that we are under pressure, but we also need to be able to work alone sometimes, without a student... and to not have to teach constantly " (16).

The stressful work environment also had an adverse effect on the students as some did not receive a good supervision and complained about missed learning opportunities:

"Everything is about time, I'd like to have more time, time to reflect, time to sit and sew with the student, and time to complete the documentation with the student before the next patient is assigned to you. Yes, I kind of feel like I don't have enough time for this student "(11).

Also management sometimes had difficulties to provide the necessary continuity in preceptorship:

“The students should not be trained by too many different midwives, a few are okay, preferably two. If they switch several times between midwives there may be a lack of continuity, depending on the schedule, and I feel sorry for them. Sometimes, there is also a human factor, like when I or my colleague get sick, for example, but this is another matter" (12).

These factors may lead midwives to think that it is too difficult to be a good preceptor which could result in a low self-efficacy. 
Support from colleagues, either in the form of regular expert meetings or as simple "corridor talk", was mentioned to be very important in order to increase self-efficacy.

Although the midwives described the regular expert meetings, both organised by the midwifery program and their workplace, as positive, they also found it difficult to make the time to attend these meetings. Midwives gave several reasons why these meetings were valuable:

Helping one another and sharing experiences helps to create a sense of community. It may also sometimes provide a new perspective on how to deal with certain issues and how to do some things better?" (7).

It was particularly useful for discussing the weaker or more problematic students, severe cases, and to lend general support and advice. Some midwives also described situations where they had been insecure about a student and how a "corridor talk" was very helpful in providing additional guidance on how to deal with the situation.

\section{Supporting the student to achieve confidence and independence}

\section{Helping the student grow}

In order to support the student to become independent, the midwives needed to help the students to develop their confidence and abilities to practice midwifery and thereby "grow" into the role as a prospective midwife. To be able to perform this task, it was necessary for the midwives to be well prepared and know the student's learning objectives and background. For instance, as students had a widely varying professional experience it was important to know how much clinical experience as a nurse they had. From the student's perspective, it was also important that they felt welcome. The midwives described many different situations in which they helped the students to develop professionally. For example, by giving the student 
confirmation and praise, by supporting them to become independent, and by nurturing their confidence in their own abilities:

"Guide them right so the student is growing ... boost the student to reflect, to let them be independent at the right time. They feel safe when they know that I am there ... and they trust that I give them the right knowledge” (17).

The midwives described various situations in which they helped the student to grow, such as giving confirmation that the student had a good communication with the expecting parents, and that the student contributed to creating a good atmosphere in the birthing room. Moreover, the midwives described how they helped the student to grow by encouraging them in different practical situations, for example, finding the "cervix” when performing vaginal examinations or attaching an electrode to the foetus' head. One midwife described another situation where the student had failed a previous course:

"She was seen, she was heard, and I noticed that she was growing” (12).

To help the student grow was also about showing respect for the student, creating a good line of communication, and making the student feel included in the team. Midwives also pointed out that seeing the student grow was the most rewarding part of being a preceptor:

"As a preceptor, it is rewarding to see people grow and learn. For example, the student might say: ”Wow, this was awesome, look what I can do". Thus, I can see it in their eyes when they feel good about themselves for having done something well; this is ..... the best reward you can get as a preceptor when you see that people grow in their role and that they are learning something" (2). 
But there were also situations where midwives stated that they could not help the students to grow. In one situation this was due to a personality mismatch:

"Sometimes there are students that I couldn't reach. Even though I tried very hard, we had poor communication and could not connect. So it does not have to be about good or bad supervision, it's so much more... yes, it is complex, I think, sometimes I succeed and sometimes I fail. Sometimes we switch preceptors and the student connects better with someone else” (4)

Reflections to facilitate learning

According to the midwives, joint sessions to reflect on the day did strengthen the student's confidence in learning situations. The reflection sessions included questions, such as: "What are you thinking here? Could you do it differently? Did you understand this? Have you learned something? Is there something missing? What are you sure about and what are you unsure about?". In addition to providing the student with an opportunity for self-reflection, the purpose of these questions was to support their learning. The midwives also expressed the importance of students providing feedback to the perceptor thereby allowing them to change or adapt their preceptorship.

According to the midwives, it was challenging to find the time for these reflection sessions with the students. Ideally, the reflections were combined with midwifery practice to maximise learning. However, the midwives also stressed the importance conducting them in a quieter environment after a day's work had ended. Additionally, the midwives stated that students should not be reprimanded in front of the expecting parents if they didn’t appear not to 
manage a situation well. Instead, students should be encouraged to handle the situation and potential suggestions for improvements should be discussed afterwards:

"I'm trying to get them to think independently first and then do the talking afterwards. I rarely say something in front of the parents to be unless it's something serious. I would never say: "don't do that, do that... " (1).

However, the midwives also described that reflection sessions could be difficult, e.g., when a student is not very receptive to critical feedback.

\section{Taking a step back}

Midwives described that once students had grown in learning situations they became more independent and the midwives could take a step back. They argued that it was important for students to be given the opportunity to act independently take their own initiative with the preceptor only supervising in the background.

The midwives described several situations where they had taken a step back by asking the students questions like "How do you think we should plan today?", "Are you ready?", "Would you like to have the main responsibility for the family?", "Do you want me do it the first time or do you want to try right away?", or through supportive statements like "I'm right behind you, try to take the first step" or "You can be the first to enter the room". By mastering a learning situation the students could boost their confidence. It was also important that the students were given the opportunity to be alone in the birthing room to establish a direct contact with the women: 
”When I see that students established a good connection with the expecting mother, my role changes. I simply make sure that everything continues to go smoothly, I think it's wonderful when you see how the student has to take the lead role, I think it's great” (17).

To take a step back was also about being humble, rather than about what was right or wrong, and it was important that the preceptor didn't take over:

"When they seemed to master the situation inside the room and knew what they needed to talk about and do next, I dared to take a step back and maybe even sit down and just be quiet. This is really an art. The greatest challenge of being a preceptor is not taking over” (14).

\section{Discussion}

Based on a survey among 17 Swedish midwives, we provided some anecdotal evidence of what it meant for them to be a good preceptor and be able to support the midwifery students to become independent in their profession. As a first step, they needed to gain experience and self-confidence as a midwife before being able to take on the role of preceptor. The increase in self-confidence can be understood as an increase in self-efficacy in their performance as midwife and preceptor (Bandura 1982). Further, the midwives expressed the need for support from both management and colleagues to develop the necessary resources and abilities to become a competent preceptor. However, self-efficacy can be both positively and negatively influenced by advice from others (Bandura 1982). Nevertheless, support from the work environment seemed to be important to the midwives and was mostly perceived as positive with regard to developing their self-efficacy. Additional aspects that were considered important for becoming a good preceptor were the ability to provide the students with learning opportunities and support their development to become more independent. Selfreflection seems to be an important outcome to facilitate student learning (Bandura 1993), 1993). Once midwives had developed a sufficient confidence in their preceptor role they were 
able to help the student grow, have reflection sessions with the students to facilitate learning, and take a step back once the student had reached a sufficient experience and confidence to act independently.

Our findings suggest that before midwives are able to take on the role of preceptor they need to have gained sufficient clinical experience to develop a "clinical eye” and achieve a holistic approach. Keeping up-to-date with new developments in the midwifery profession, both through access to literature and the opportunity to participate in special training courses would increase their ability to supervise students. There exists a critical shortage of midwives in many countries (McKellar and Graham 2017), including Sweden, which has had the adverse effect that midwives had to start take on students regardless of their level of clinical experience or preceptor training. In line with McKellar and Graham (2017), we found that a supportive management that allow the necessary time to carry out their duties as a preceptor is very important. Furthermore, support from colleagues both in formal and informal settings were also identified as being important for the professional development of perceptors. In agreement with previous studies, continuity in preceptorship was identified as an important factor for establishing personal workplace relationships (Brunstad and Hjalmhult 2014; Gilmour et al. 2013; Hauck et al. 2017; Thunes and Sekse 2015), for understanding workplace culture (Gilmour et al. 2013; Hauck et al. 2017) and to not have to repeat already acquired learning goals (Hauck et al. 2017). Moreover, a lack of continuity had a generally negative impact on student learning (Gilmour et al. 2013).

Our findings also suggest that once midwives had developed their self-efficacy in the preceptor role, they became better at boosting the student's confidence and learning through affirmation, praise, and general support, e.g., self-reflection sessions (Bandura 1993). 
According to the midwives, these preceptorship techniques increased the students' confidence and thus their self-efficacy (Bandura 1982). It also afforded the preceptor to opportunity to “take a step back” and let the students work more independently. Some of these findings correspond to other studies that described the students' perceptions on what increased their confidence. For example, students need to feel accepted and included in the ward (Brunstad and Hjalmhult 2014; Thunes and Sekse 2015) which was facilitated by more practical and hands-on learning situations (Hauck et al. 2017; Hughes and Fraser 2011; Licqurish and Seibold 2008; Thunes and Sekse 2015). This corresponds to Banduras (1982) who stated that one learns through observation, imitation, and availability of good role models. Our findings also align with other studies with regard to the importance of building a relationship of trust with the students (Brunstad and Hjalmhult 2014; Gilmour et al. 2013) and the importance of being caring and enjoying the preceptor role (Licqurish and Seibold 2008). The midwives in our study also described situations where they student-perceptor relationship did not work well due to personality mismatches, a lack of time by the preceptor, or a lack of continuity in preceptorship. This correspond to findings by other studies with regard to possible student vulnerabilities during their clinical placements (Back et al. 2017; Brunstad and Hjalmhult 2014; Davies and Coldridge 2015; Licqurish and Seibold 2008; Licqurish and Seibold 2013; Schytt and Waldenstrom 2013; Thunes and Sekse 2015). In line with other studies, we also found that reflection are key to facilitate learning (Brunstad and Hjalmhult 2014; Ekelin et al. 2016; Embo et al. 2015; Longworth 2013).

The process of becoming a good preceptor and facilitate learning for the students is challenging. It is not enough for a student to be motivated in order to achieve the desired learning outcomes in a clinical setting (Thunes and Sekse 2015) but the preceptor also needs to be sufficiently motivated to teach and facilitate learning (Gilmour et al. 2013). This 
motivation is linked to a high degree of self-efficacy in the preceptor (Bandura 1982) as this will motivate preceptor to invest more time and effort into the preceptorship activities and remain persistent when faced with adverse conditions. Another key factor is that students observe their preceptors and learn from their actions (rather than from their words), which makes it important for preceptors to act as good role models all the time in order to transmit the correct attitudes and values to the students (Bandura 1993). Some studies have shown that midwives are positive role models for the student midwives (Hauck et al. 2017; Licqurish and Seibold 2008).

Since all participants were recruited from three hospitals located in the same Swedish city, our findings may not be fully transferable to other localities. To minimize bias due to the authors' preconceptions and presumptions when interpreting the transcribed text, all authors independently analysed the data during all phases of analysis. Although the study sample was small, the findings and knowledge derived from the collected data can be useful to develop preceptorship courses.

\section{Conclusions}

Midwife preceptors are crucial for training students during their transition to become certified midwives. However, our findings showed that preceptorship is a demanding and complex task. The relationship between preceptor and student are crucial to facilitate a good learning outcome and to boost confidence. We found that good preceptorship is directly related to the midwives’ perception of self-efficacy, i.e., by increasing their mastery of the preceptor role they were better able to help the student achieve confidence and independence. This new result represents an advancement to further the development of preceptorship and a health care organisations that support preceptorships. 


\section{Reference}

Back L, Sharma B, Karlstrom A, Tunon K, Hildingsson I (2017) Professional confidence among Swedish final year midwifery students - A cross-sectional study. Sexual \& Reproductive Healthcare 14:69-78 doi:10.1016/j.srhc.2017.10.003

Bandura (1982) Self-efficacy mechanism in human agency. American Psychologist 37(2):122-147

Bandura A (1993) Perceived self-efficacy in cognitive development and functioning. Educational Psychologist 28:117-148

Braun VCV (2006) Using thematic analysis in psychology. Qualitative Research in Psychology 3 (2):77-101

Brunstad A, Hjalmhult E (2014) Midwifery students learning experiences in labor wards: a grounded theory. Nurse education today 34(12):1474-9 doi:10.1016/j.nedt.2014.04.017

Davies S, Coldridge L (2015) 'No Mans Land': An exploration of the traumatic experiences of student midwives in practice. Midwifery 31(9):858-64 doi:10.1016/j.midw.2015.05.001

Ekelin M, Kvist LJ, Persson EK (2016) Midwifery competence: Content in midwifery students' daily written reflections on clinical practice. Midwifery 32:7-13 doi:10.1016/j.midw.2015.10.004

Embo M, Driessen E, Valcke M, van der Vleuten CPM (2015) Relationship between reflection ability and clinical performance: A cross-sectional and retrospectivelongitudinal correlational cohort study in midwifery. Midwifery 31(1):90-94 doi:10.1016/j.midw.2014.06.006

Gilmour C, McIntyre M, McLelland G, Hall H, Miles M (2013) Exploring the impact of clinical placement models on undergraduate midwifery students. Women and Birth 26(1):E21-E25 doi:10.1016/j.wombi.2012.06.004

Hauck Y, Lewis L, Pemberton A, Crichton C, Butt J (2017) 'Teaching on the Run' with Australian midwives in a tertiary maternity hospital. Nurse education in practice 22:47-54 doi:10.1016/j.nepr.2016.11.006

Hughes AJ, Fraser DM (2011) "There are guiding hands and there are controlling hands": Student midwives experience of mentorship in the UK. Midwifery 27(4):477-483 doi:10.1016/j.midw.2010.03.006

Jordan R, Farley CL (2008) The confidence to practice midwifery: preceptor influence on student self-efficacy. J Midwifery Womens Health 53(5):413-20 doi:10.1016/j.jmwh.2008.05.001

Licqurish S, Seibold C (2008) Bachelor of Midwifery students' experiences of achieving competencies: the role of the midwife preceptor. Midwifery 24(4):480-9 doi:10.1016/j.midw.2007.05.001

Licqurish S, Seibold C (2013) 'Chasing the numbers': Australian Bachelor of Midwifery students' experiences of achieving midwifery practice requirements for registration. Midwifery 29(6):661-7 doi:10.1016/j.midw.2012.06.006

Longworth MK (2013) An exploration of the perceived factors that affect the learning and transfer of skills taught to student midwives. Midwifery 29(8):831-7 doi:10.1016/j.midw.2012.07.013

McClure E, Black L (2013) The role of the clinical preceptor: an integrative literature review. The Journal of nursing education 52(6):335-41 doi:10.3928/01484834-20130430-02 
McIntosh AE, Gidman J, McLaughlin A (2013) Students' and lecturers' perceptions of support in a UK pre-registration midwifery programme. Nurse education in practice 13(6):578-83 doi:10.1016/j.nepr.2013.01.015

McKellar L, Graham K (2017) A review of the literature to inform a best-practice clinical supervision model for midwifery students in Australia. Nurse education in practice 24:92-98 doi:10.1016/j.nepr.2016.05.002

Moran M, Banks D (2016) An exploration of the value of the role of the mentor and mentoring in midwifery. Nurse education today 40:52-6 doi:10.1016/j.nedt.2016.02.010

Schytt E, Waldenstrom U (2013) How well does midwifery education prepare for clinical practice? Exploring the views of Swedish students, midwives and obstetricians. Midwifery 29(2):102-109 doi:10.1016/j.midw.2011.11.012

Thorstensson S, Nissen E, Ekstrom A (2008) An exploration and description of student midwives' experiences in offering continuous labour support to women/couples. Midwifery 24(4):451-459 doi:10.1016/j.midw.2007.05.003

Thunes S, Sekse RJT (2015) Midwifery students first encounter with the maternity ward. Nurse education in practice 15(3):243-248 doi:10.1016/j.nepr.2015.01.012 